\title{
The use of scintillometry for validating aggregation schemes over heterogeneous grids
}

a Université Cadi Ayyad/Institut de Recherche pour le Développement, Marrakech, Morocco

${ }^{\mathrm{b}}$ Institut de Recherche pour le Développement/Centre d'Etudes Spatiales de la Biosphère BP 31401 cedex Toulouse, France

\section{A R T I C L E I N F O}

\section{Article history:}

Received 2 November 2008

Received in revised form 5 September 2009 Accepted 9 September 2009

\section{Keywords:}

Scintillometry

Aggregation scheme

Evapotranspiration

Heterogeneous grid

Semi-arid regions

\section{A B S T R A C T}

A number of studies have been devoted to derive the diurnal course of regional evapotranspiration (ET) especially in semi-arid areas where the assessment of this term is of crucial importance for water resources management. One approach to derive regional evapotranspiration is based on the use of aggregation schemes in conjunction with energy-balance or land-surface models. However, the effectiveness of this approach cannot be fully assessed without a comparison between the model's flux simulations and the ground truth observations. In the present study, the issue of using scintillometry for validating spatial and temporal aggregation schemes over heterogeneous grids has been investigated. Data collected within the SUDMED project over the oliveyard of Agdal which was located near the Marrakech city (Morocco), have been used to test the aggregation schemes. The Agdal oliveyard was made up of two contrasted fields, or patches. Even though the two sites appear relatively homogeneous, they differ strongly in terms of soil moisture status and vegetation percent cover. The higher soil moisture in the northern site creates heterogeneity at the scale of the entire olive yard (i.e. at grid-scale).

Firstly, the diurnal course of the grid-scale evapotranspiration $\left(\left\langle\mathrm{ET}_{\mathrm{sim}}\right\rangle_{\mathrm{SA}}\right)$ estimated from spatial aggregation scheme is compared to that derived from the scintillometry $\left(\left\langle\mathrm{ET}_{\mathrm{LAS}}\right\rangle\right)$. The $\left\langle\mathrm{ET}_{\mathrm{Sim}}\right\rangle_{\mathrm{SA}}$ is obtained as the residual term of the energy balance providing the estimates of the available energy ( $\mathrm{AE}\left(=R_{\mathrm{n}}-G\right)$, where $R_{\mathrm{n}}$ and $G$ are the net radiation and the soil heat flux, respectively, and sensible heat flux. Thelatter is estimated by using a simple two-layer model developed by Lhomme et al. (1994). The root mean square difference (RMSD) and the correlation coefficient $\left(R^{2}\right)$ between $\left\langle\mathrm{ET}_{\text {sim }}\right\rangle_{\mathrm{SA}}$ and $\left\langle\mathrm{ET}_{\mathrm{LAS}}\right\rangle$ were about $46 \mathrm{~W} \mathrm{~m}^{-2}$ and 0.78 , respectively. Secondly, we compared the diurnal course of the grid-scale evapotranspiration $\left(\left\langle\mathrm{ET}_{\mathrm{Sim}}\right\rangle_{\mathrm{TA}}\right)$ estimated from the temporal aggregation scheme with the $\left\langle\mathrm{ET}_{\mathrm{LAS}}\right\rangle$. $\left\langle\mathrm{ET}_{\operatorname{sim}}\right\rangle_{\mathrm{TA}}$ is obtained by extrapolating the instantaneous values of the available energy and the evaporative fraction $(\mathrm{EF}(=\mathrm{ET} / \mathrm{AE})$ estimated at the satellite overpass to daily ones. The instantaneous values of $\mathrm{AE}$ and $\mathrm{EF}$ have been derived using remotely sensed surface temperature measured using a ground-based infrared thermometer combined with ancillary micrometeorological data such as wind speed, incoming and outgoing solar radiation, and temperature and humidity of the air. The RMSD and the $R^{2}$ were about $43 \mathrm{~W} \mathrm{~m}^{-2}$ and 0.7 , respectively. Despite the complexity of the site induced by the strong heterogeneity in the soil moisture which is related to the employed irrigation method (flood irrigation), and the consequences in terms of the footprint of the instruments, the obtained statistical results showed that both aggregation schemes performed successfully with regard to estimates of the evapotranspiration over heterogeneous grids.

Finally, to further assess the performance of the developed approach, a second dataset collected in northern Mexico has been also used. The result shows that the approach provides acceptable values of aggregated evapotranspiration. Consequently, scintillometry can potentially be used in the development and the validation of aggregation approaches to improve the representation of surface heterogeneity land-surface-atmosphere models operating at large scales.

(c) 2009 Published by Elsevier B.V.

\section{Introduction}

* Corresponding author at: SUDMED Program, Centre Geber, salle 26, Faculté des Sciences Semlalia, Université Cadi Ayyad, BP 2390 Marrakech, Morocco. Tel.: +212 244316 26; fax: +21224431626.

E-mail address: j.ezzahar@ucam.ac.ma (J. Ezzahar).
Regions classified as semi-arid or arid constitute roughly onethird of the total global land surface. In these regions, due to the combined effect of human intervention and the expected modification of precipitation pattern water managers are faced

\section{9}


with several challenges. Among them, water resource scarcity combined to increase of water demands, competition among different water user groups, which lead to over-exploitation of aquifers. The serious environmental and socio-economic consequences of these factors have led the earth science community to investigate the issue of the impact of human and natural induced changes on the hydrological cycle and water resources with the ultimate objective of developing tools so that managers and politicians can make decisions based on state of the art science. In this context, a strong emphasis has been directed toward understanding the processes controlling the exchanges of water and energy between the land surface and the atmosphere. Due to the importance of the evapotranspiration (ET) flux in the water cycle, especially in arid and semi-arid regions, efforts have been particularly oriented toward improving its estimates at different space-time scales. However, quantifying diurnal ET variation over large and heterogeneous areas is not straightforward (Kustas and Norman, 2000).

In this regard, remotely sensed data can be a valuable tool to address this issue (Kustas and Norman, 1996, 1999; Kustas et al., 2001, 2004; Norman et al., 1995, 2003, 2006). Geostationary sensors can provide regional scale of ET with temporal sampling from 15 min to $1 \mathrm{~h}$, but their spatial resolution is very coarse. In fact, a single pixel may contain surfaces with widely varying characteristics (mixed fields), which make the interpretation of the data very difficult. In contrast, sun-synchronous satellites provide data with better spatial resolution, but the temporal resolution is poor. Therefore the issue of discrepancy between the space-time scale of satellite observation and that at which the process needs to be described is still an open research question (McCabe and Wood, 2006).

For the purpose of irrigation management, the combination of the sun-synchronous sensors data and aggregation schemes can provide a workable solution (Chehbouni et al., 2008a). The aggregation scheme is conceived as a method which seeks to link the model parameters that control surface exchange on a patch scale with the area-average value of equivalent model parameters applicable on a larger scale or grid-scale, assuming that the same equations are used to describe surface fluxes at both scales. In this regard, substantial progress has been made in the last decade to develop aggregation schemes which range from physically based through semi-empirical, to entirely empirical (Braden, 1995; Chehbouni et al., 1995; Raupach and Finnigan, 1995) or experimental studies (Arain et al., 1996; Blyth and Harding, 1995; Chehbouni et al., 2000a; Moran et al., 1997; Noilhan et al., 1997; Sellers et al., 1997). However, one of the main difficulties regarding the development of these aggregation procedures is the evaluation of their outputs/performances against ground observations. The straightforward solution is to deploy a network of patch scale measurement devices such as eddy correlation systems. However, due to the high cost of the devices and the requirement for continuous availability of well-trained staff to operate and maintain them, this solution cannot be implemented on an operational basis.

In this context, scintillometry can be considered as an attractive method for routinely measuring area-averaged surface fluxes. Using a Large Aperture Scintillometer (LAS), one can obtain areaaveraged surface fluxes over distances from a few hundred metres up to several kilometres. Recently, several investigations have indeed demonstrated its potential to derive area or path average of the sensible heat flux over large and heterogeneous surfaces (Asanuma and Lemoto, 2006; Chehbouni et al., 1999, 2000b, in press; Ezzahar et al.,2007a, 2009; Hoedjes et al., 2007; Kleissl et al., 2006; Lagouarde et âl., 2002; Marx et al., 2008; Watts et al., 2000). The combination of LAS measurements and estimates of available energy can provide reasonable retrieval of area-averaged ET as the residual term of the energy-balance equation (Chehbouni et al., 2000b, in press; Ezzahar et al., 2007b, 2009; Hemakumara et al., 2003). Consequently, the scintillometer (LAS), is becoming popular in hydrometeorological studies, because it is relatively cheap, robust and easy to operate and maintain.

The main objective of the current study is to assess whether the LAS can be used to validate spatial and temporal aggregation schemes at grid-scale by comparing the ET derived from the LAS and those estimated from both aggregation methods. For the spatial aggregation method, the ET was obtained as the residual term of the energy balance providing the estimates of the available energy and sensible heat flux using ground-based radiometric surface temperature measurements and an ancillary micrometeorological data. For the temporal aggregation method, the ET was obtained by extrapolating the instantaneous values of the available energy and the evaporative fraction estimated at the satellite overpass to daily ones using a simple heuristic approach developed by Chehbouni et al. (2008a). This approach used the radiometric surface temperature derived at the satellite overpass and an ancillary micrometeorological data. The particularity of the studied is related to two factors. First, the nature of the study site is very complex: tall, sparse, large and contrasted olive trees fields and the method employed for irrigation (flood irrigation) which amplifies the heterogeneity of the grid. Second, as far as we know, this is the first study where that the LAS has been used to validate both spatial and temporal aggregation schemes.

\section{Experiment site and measurements}

The experiment was carried out in the fall of 2002, between day of year (DOY) 295 and 306 (22 October to 2 November) in a 275-ha Agdal olive orchard which is located to the southeast of Marrakech, Morocco $\left(31^{\circ} 36^{\prime} \mathrm{N}, 07^{\circ} 58^{\prime} \mathrm{W}\right)$. This experiment was a part of the SUDMED project (Chehbouni et al., 2008b) which took place in southern Mediterranean region (Marrakech, Morocco), to assess the spatio-temporal variability of water needs and consumption for irrigated crops during water shortages. In this section, site description and experimental set-up are briefly summarized; the

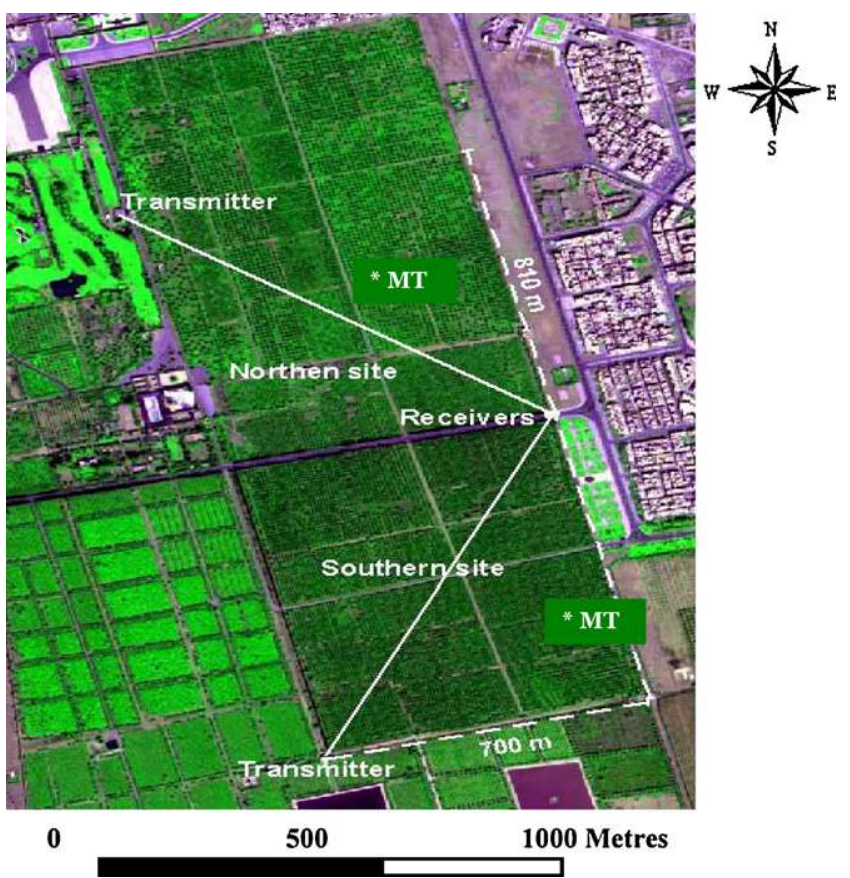

Fig. 1. Overview of the location site and the experimental setup (Quickbird image). The locations of LAS and micrometeorological towers (MT) are marked. 
reader is referred to Ezzahar et al. (2007a) for a complete description. Fig. 1 displays the area of interest on a very high spatial resolution image acquired by the Quickbird satellite. The climate is typically semi-arid Mediterranean; precipitation falls mainly during winter and spring (about $75 \%$ of the total precipitation), from the beginning of November until the end of April, with an average ranging from 192 to $253 \mathrm{~mm}$ per year. The atmosphere is dry with an average relative humidity of $56 \%$ and the evaporative demand is very high (1600 mm per year, Er-Raki et al., 2008), greatly exceeding the annual rainfall.

The experimental area is divided into two sites, which were relatively homogeneous in terms of vegetation types, but differ strongly in characteristics (mainly soil moisture status, and, to a lesser extent, vegetation percent cover). These sites are referred to as the "southern site" and the "northern site" (see Fig. 1). The average height of the olive trees during the experiment period was $6.5 \mathrm{~m}$ at the southern site and $6 \mathrm{~m}$ at the northern site. The mean fraction cover was approximately $55 \%$ at the southern site and $45 \%$ at the northern site, as obtained from hemispherical canopy photographs (using a Nikon Coolpix $950^{\circledR}$ with a FC-E8 fish-eye lens converter, field of view $183^{\circ}$ ).

Both sites were equipped with a set of standard meteorological instruments to measure wind speed and direction (model Wp200, R.M. Young Co., Traverse City, MI, USA); air temperature and humidity (model HMP45AC, Vaisala Oyj, Helsinki, Finland) at $9 \mathrm{~m}$ above the ground. These instruments were set up $9 \mathrm{~m}$ above ground. Net radiation was measured using net radiometers (a model CNR1, Kipp and Zonen, Delft, The Netherlands at the southern site and a model Q7, REBS Inc., Seattle, WA, USA at the northern site). These radiometers were placed at $8.5 \mathrm{~m}$ height to embrace vegetation and soil radiances by ensuring the field of view was representative of their respective cover fractions. The CNR1 measures the four components of the net radiation, i.e. independent estimates incoming and outgoing solar and far-infrared radiation. In order to calculate the albedo over the northern site, two pyranometers (model CM5, Kipp \& Zonen, Delft, The Nether- lands) were mounted to measure incoming and outgoing shortwave radiation. Soil and vegetation surface temperatures were measured using two infrared thermometers (model IRTS-Ps, Apogee Instruments Inc., Logan, UT, USA), with a 3:1 field of view, at heights of 1 and $8.4 \mathrm{~m}$ respectively. Soil heat flux density was measured at a depth of $0.01 \mathrm{~m}$ using soil heat flux plates (HFT3-L, Campbell Scientific Ltd.) which were installed at three locations in order to get good average values; underneath the canopy (always shaded), in between the trees (mostly sunlit), and in an intermediate position. Time Domain Reflectometery (TDR) probes (model CS616, Campbell Scientific Ltd.) were installed at depth of $0.05 \mathrm{~m}$ to measure soil water content. Their outputs have been calibrated using the gravimetric method. The slope, the intercept and the correlation coefficient of the obtained linear regression were $66,-58$ and 0.96 respectively. Measurements were taken at $1 \mathrm{~Hz}$, and averages stored at 30-min intervals on CR10X data loggers (Campbell Scientific Ltd.). The prevailing wind direction during the study period was from the northwest. The half-hourly values of the measured climatic variables including the air temperature, air relative humidity, incoming solar radiation, and wind speed are shown in Fig. 2.

Besides the standard meteorological measurements, two eddy covariance systems were installed to provide continuous measurements of the vertical fluxes of heat, water vapour and $\mathrm{CO}_{2}$ at a height of 8.8 and $8.7 \mathrm{~m}$ for the southern and northern sites, respectively. The EC systems consisted of a 3D sonic anemometer (CSAT3, Campbell Scientific Ltd.) and an open-path infrared gaz analyzer (Li7500, Licor Inc.). Raw data were sampled at a rate of $20 \mathrm{~Hz}$ and were recorded using CR23X dataloggers (Campbell Scientific Ltd.) which were connected to portable computers to enable storage of large raw data files. The half-hourly values of fluxes were later calculated off-line after performing coordinate rotation, frequency corrections, correcting the sonic temperature for the lateral velocity and presence of humidity, and the inclusion of the mean vertical velocity according to Webb et al. (1980). Data from the eddy covariance system were processed using the
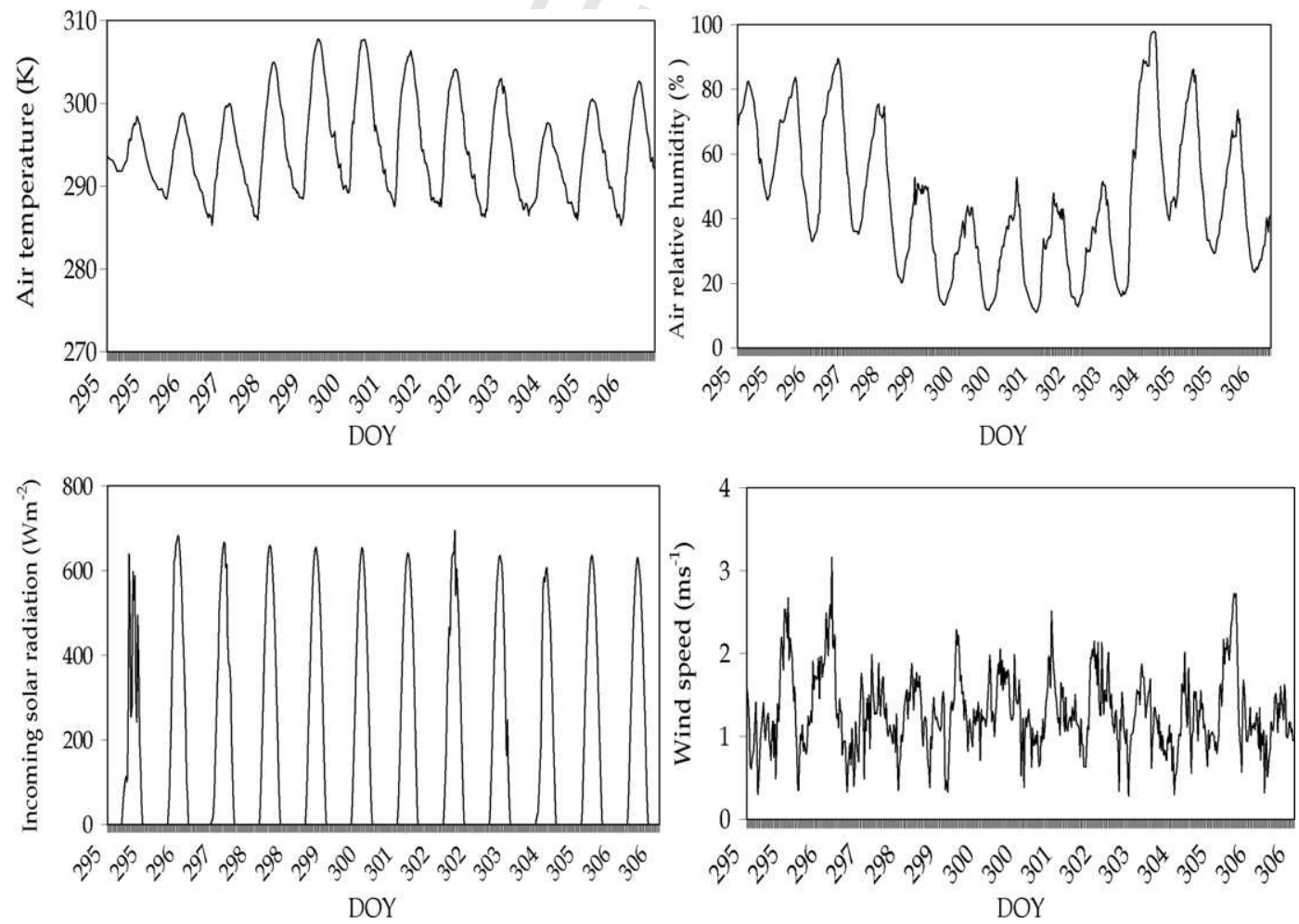

Fig. 2. Half-hourly values of weather variables during the study period. 
software 'ECpack' developed by the Meteorology and Air Quality group, Wageningen University (available for download at http:// www.met.wau.nl/).

Two identical Large Aperture Scintillometers were mounted at heights of $14 \mathrm{~m}$ in the southern site and $14.5 \mathrm{~m}$ in the northern site (see Fig. 1). These instruments were constructed by the Meteorology and Air Quality Group (Wageningen Agriculture University, The Netherlands) and were originally designed by Ochs and Wilson (1993). They have an aperture size of $0.15 \mathrm{~m}$ and the transmitter operates on a wavelength of $0.94 \mu \mathrm{m}$. At the receiver, $C_{n}^{2}$ is sampled at $1 \mathrm{~Hz}$ and stored as 1-min averages using a CR510 data logger (Campbell Scientific Ltd.). Over the southern site, the LAS was installed perpendicular to the dominant wind direction, over a path length of $1050 \mathrm{~m}$. The transmitter was mounted on a tripod installed on a roof, located on the southwest corner of the southern site, while the receiver was mounted on a 15-m-high tower that was positioned next to the road that separates the two sides of the orchard. Over the northern site, the LAS was almost parallel to the dominant wind direction, and it measured over a path length of $1070 \mathrm{~m}$. The transmitter was mounted on a tripod installed on a roof located near the northern corner of the northern site. The receiver was installed on the same tower as the receiver of the LAS installed over the northern site in such a manner that the two signals did not interfere. The measured values of $C_{n}^{2}$ were used to derive the sensible heat fluxes (see Appendix A) and the evapotranspiration from the LAS was calculated by imposing the energy-balance closure assumption using the measured net radiation and the measured soil heat flux. Ezzahar et al. (2007a) have evaluated the accuracy of the both scintillometers by comparing the derived sensible heat fluxes with those measured with eddy covariance systems for the same period of the current study. The obtained linear regression yielded a slope of 0.95 (1), correlation coefficient of $0.89(0.74)$ and a root mean square difference of $24 \mathrm{~W} \mathrm{~m}^{-2}\left(27 \mathrm{~W} \mathrm{~m}^{-2}\right)$ for the southern site (northern site). The statistical results of these comparisons showed a better agreement for the southern site than for the northern site due to the contrast between the two sites in terms of water availability. Indeed, in addition to the difference in the cover and height of vegetation between the two sites, the period of this study was chosen in order to have a distinct difference between the two sites in term of soil moisture. The southern site was dry and the northern site had just been irrigated. Fig. 3 shows the evolution of the volumetric water content throughout the experiment. From Fig. 3, it is clear that the grid, comprised of the northern and southern sites, is very heterogeneous. Therefore, this study presents a good opportunity to estimate the ET over heterogeneous grids.

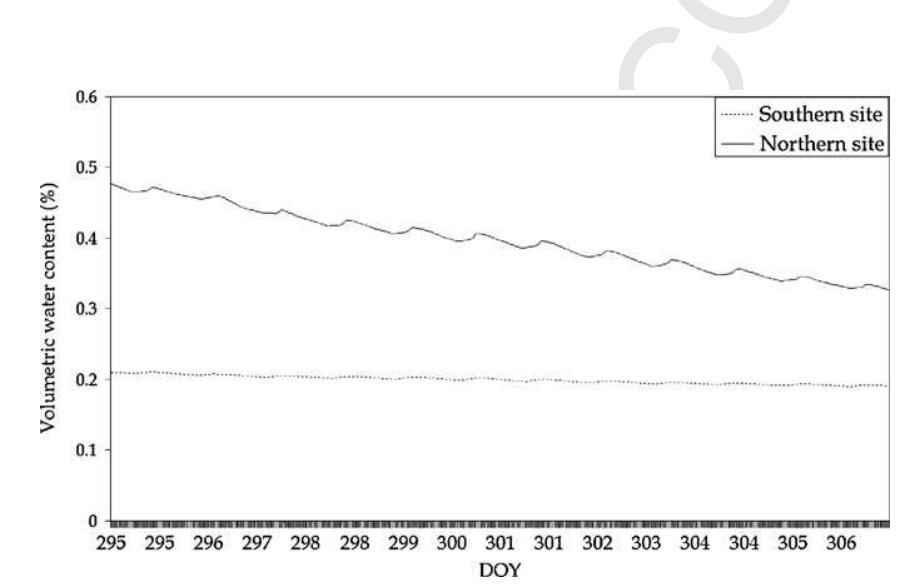

Fig. 3. Evolution of the volumetric water content during the experimental period for the southern site (dotted line) and northern site (solid line).

\section{Modeling approach}

\subsection{Model for surface flux estimates}

\subsubsection{Sensible heat flux}

For homogeneous vegetation cover conditions, a single-source Soil-Vegetation-Atmosphere Transfer (SVAT) model may be suitable for estimating the sensible heat flux; however in most cases the landscape is under partial vegetation canopy so that soil and vegetation contribution to the sensible heat flux exchange should be explicitly taken into account (Norman et al., 1995). For more complex canopies as the present study site, a two-source energy-balance model provides a more realistic representation of the sensible heat flux exchanges with the lower atmosphere (Lhomme et al., 1994; Merlin and Chehbouni, 2004; Norman et al., 2000). In this specific study, the sensible heat flux is estimated using the simple two-layer model developed by Lhomme et al. (1994). Here, only a brief description of the model is provided, the reader is referred to Lhomme et al. (1994) for a complete description. According to Lhomme et al. (1994), the sensible heat flux at the patch scale is expressed as follows:

$H_{\mathrm{Mod}}=\rho c_{p}\left[\frac{\left(T_{\mathrm{R}}-T_{\mathrm{a}}\right)-c \delta T}{r_{\mathrm{a}}-r_{\mathrm{e}}}\right]$

where $r_{\mathrm{a}}$ is the aerodynamic resistance to heat transfer between the level of apparent sink of momentum and the reference height $\left(\mathrm{sm}^{-1}\right)$ (Brutsaert, 1982). $r_{\mathrm{a}}$ is calculated using the classical formulae which take into account the stability correction functions for wind and temperature (Brutsaert, 1982). $T_{\mathrm{R}}$ is the surface temperature $(\mathrm{K})$, and $r_{\mathrm{e}}$ is the equivalent resistance defined by:

$r_{\mathrm{e}}=\frac{r_{\mathrm{af}} r_{\mathrm{as}}}{r_{\mathrm{af}}+r_{\mathrm{as}}}$

where $r_{\text {as }}$ is the aerodynamic resistance between the soil and the canopy source height (Shuttleworth and Gurney, 1990) and $r_{\mathrm{af}}$ is the bulk boundary layer resistance of the canopy (Choudhury and Monteith, 1988). The term $\delta T$ represents the temperature difference between the foliage and the soil. Lhomme et al. (1994) have linked statistically $\delta T$ to $\left(T_{\mathrm{R}}-T_{\mathrm{a}}\right)$ by the following empirical equation:

$\delta T=a\left(T_{\mathrm{R}}-T_{\mathrm{a}}\right)^{m}$

Finally $c$ is given by

$c=\left[\frac{1}{1+\left(r_{\mathrm{af}} / r_{\mathrm{as}}\right)}\right]-f_{v}$

where $f_{v}$ is the fractional vegetation cover, $a$ and $m$ are empirical coefficients (a positive real number and $\mathrm{m}$ positive integer) which were determined statistically by adjusting $H$ estimated to $H$ observed. The value of 0.25 and 2 were used respectively for $a$ and $m$ (Hoedjes et al., 2008)

\subsubsection{Available energy}

In general, the estimation of the evapotranspiration as the residual term of the energy-balance equation over a heterogeneous grid requires, addifionally to the sensible heat flux estimates, a network of the net radiometers and the soil heat flux in order to capture the heterogeneity of the grid, which is also costly and not really feasible for operational purposes. Therefore, we proposed to estimate the available energy using a simple model which uses radiometric surface temperature, albedo and incoming solar radiation data (Chehbouni et al. (2008a)). This model is described as follows: 
3.1.2.1. Net radiation. The net radiation quantifies the energy available for crop evapotranspiration, photosynthesis, and soil heating (Monteith and Unsworth, 1990). It is the difference between the incoming and outgoing shortwave and long wave radiation fluxes, and is expressed as follows:

$R_{\mathrm{n}}=(1-\alpha) R_{\mathrm{g}}+\varepsilon_{\mathrm{s}} R_{\mathrm{a}}-R_{\mathrm{t}}$

where $\alpha$ is the surface albedo, $R_{\mathrm{g}}$ is the global solar radiation, $\varepsilon_{\mathrm{s}}$ is the surface emissivity which has an almost constant value (in Q1 practical work a value of 0.98 , may be taken for crop canopies; Ortega et al., 2000; Jones et al., 2003), $R_{\mathrm{a}}$ the atmosphere thermal radiation and $R_{\mathrm{t}}$ is the thermal radiation which is emitted by the surface. Both $R_{\mathrm{a}}$ and $R_{\mathrm{t}}$ can be expressed in function of air temperature and surface temperature (Monteith and Unsworth, 1990; Duarte et al., 2006), respectively. Then, Eq. (5) can be rewritten as:

$R_{\mathrm{n}}=(1-\alpha) R_{\mathrm{g}}+\varepsilon_{\mathrm{s}} \sigma\left(\varepsilon_{\mathrm{a}} T_{\mathrm{a}}^{4}-T_{\mathrm{R}}^{4}\right)$

where $\sigma$ is the Stefan-Boltzman constant and $\varepsilon_{\mathrm{a}}$ is the emissivity of the atmosphere.

Several authors have proposed empirical relationships which relate the atmospheric emissivity to the air temperature (Angstrom, 1918; Brunt, 1932; Idso, 1981). For clear skies, Brutsaert (1975) has computed $\varepsilon_{\mathrm{a}}$ from air temperature and vapour pressure as:

$\varepsilon_{\mathrm{a}}=1.24\left(\frac{e_{\mathrm{a}}}{T_{\mathrm{a}}}\right)^{1 / 7}$

where $e_{\mathrm{a}}$ is the air vapour pressure (hPa). In what follows, this equation will be used without including any correction for the effect of clouds, because as shown as shown in Fig. 2, the experimental period contained only a few cloudy data.

3.1.2.2. Soil heat flux. The soil heat flux $(G)$, which is a function of the thermal conductivity of the soil and the vertical temperature gradient, is difficult to obtain in a physical-based manner over large heterogeneous areas. Several researchers have parameterized $G$ as a constant proportion of $R_{\mathrm{n}}$ (i.e. $G=c R_{\mathrm{n}}$ ) that is fixed for the entire day or period of interest (Mecikalski et al., 1999; Norman et al., 1995, 2000; Crawford et al., 2000; Su, 2002). Recommended values for $G / R_{\mathrm{n}}$ are around 0.30 for sparse canopies but values ranging from 0.15 to 0.40 have been reported in the literature (Brutsaert, 1982; Choudhury, 1987; Humes et al., 1994; Kustas and Goodrich, 1994). Recently, Santanello and Friedl (2003) have reported that $G$ is unfortunately neither constant nor negligible on diurnal time scales. $G / R_{\mathrm{n}}$ can range from 0.05 to 0.50 and is driven by several factors: time of day, soil moisture and thermal properties, as well as the amount and height of vegetation (Kustas et al., 1993). In the current study, the ratio of the soil heat flux to net radiation was estimated according to Santanello and Friedl (2003) as follows:

$\frac{G}{R_{\mathrm{n}}}=A \cos \left[\frac{2 \pi(t+10800)}{B}\right]$

where $t$ is the time of day in seconds, and $A$ and $B$ are adjusting factors which were set by Santanello and Friedl (2003) as 0.31 and $74000 \mathrm{~s}$, respectively. Using the same factors, this model was used with success over a wide range of climate and surface conditions (Hoedjes et al., 2008; Chehbouni et al., 2008a; and Ezzahar et al., 2009).

Provided that sensible heat flux $H$, net radiation $R_{\mathrm{n}}$ and soil heat flux $G$ estimates are obtained using the aforementioned formulations, estimated latent heat flux ET can be derived as the residual term of the energy-balance equation.

\subsection{Aggregation procedures}

In this section, two aggregation algorithms are presented to estimate the diurnal course of evapotranspiration at the grid-scale: spatial aggregation which consists of upscaling the patch measurements/or estimates to grid-scale estimates and the temporal aggregation which consists of extrapolating the gridscale instantaneous values which can be derived from remote sensing to daily ones. In what follows, the area-averaged over the grid is denoted by the angle brackets, $\Lambda$ '

\subsubsection{Spatial aggregation}

In the following, the theory which underlies essential aspects of the application of the spatial aggregation algorithm to formulate the grid-scale surface fluxes is described. The spatial aggregation is conceived as a method which seeks to link the model parameters which control surface exchange on a patch scale with the areaaverage value of equivalent model parameters applicable at larger, model grid-scale, and to adopt the equations that are accepted as reasonable descriptions of surface-atmosphere exchanges at the patch scale to describe the area-averaged behavior of heterogeneous cover on the grid-scale. The strategy adopted in this current study to infer grid-scale surface fluxes is based on two assumptions (Shuttleworth et al., 1997; Chehbouni et al., 2000a, 2008a): the first one consists in determining grid-scale surface fluxes in such a way that the flux equations on the grid-scale must have the same form as those used on a patch scale but whose arguments are the aggregate expressions of those on the patch scale. The second one stipulates that "the effective or area-average value of land surface parameters is estimated as a weighted average over the component cover types in each grid through that function involving the parameter which most succinctly expresses its relationship with the associated surface flux" (Shuttleworth et al., 1997). Expressions of grid-scale surface fluxes (denoted by angle brackets) resulting from the application of this simple aggregation rule are given below:

$\left\langle R_{\mathrm{n}}\right\rangle=(1-\langle\alpha\rangle) R_{\mathrm{g}}+\left\langle\varepsilon_{\mathrm{s}}\right\rangle \sigma\left(\varepsilon_{\mathrm{a}} T_{\mathrm{a}}^{4}-\left\langle T_{\mathrm{S}}^{4}\right\rangle\right)$

$\frac{\langle G\rangle}{\left\langle R_{\mathrm{n}}\right\rangle}=A \cos \left[\frac{2 \pi(t+10800)}{B}\right]$

$\left\langle H_{\text {Sim }}\right\rangle=\rho c_{p}\left[\frac{\left(\left\langle T_{\mathrm{R}}\right\rangle-T_{\mathrm{a}}\right)-\left[\left(\left\langle r_{\mathrm{as}}\right\rangle /\left\langle r_{\mathrm{as}}\right\rangle+\left\langle r_{\mathrm{af}}\right\rangle\right)-f\right]\left(a\left(\left\langle T_{\mathrm{R}}\right\rangle-T_{\mathrm{a}}\right)^{m}\right)}{\left\langle r_{\mathrm{a}}\right\rangle-\left\langle r_{\mathrm{e}}\right\rangle}\right]$

Similarly, the application of the second assumption leads to the following set of relationships between local (subscript $i$ ) and effective (in brackets) radiative temperature, surface emissivity, surface albedo, displacement height and roughness length (Chehbouni et al., 2008a):

$\left\langle T_{\mathrm{R}}\right\rangle=\left[\frac{\sum_{i} f_{i} \varepsilon_{i}\left(T_{\mathrm{R} i}\right)^{4}}{\langle\varepsilon\rangle}\right]^{0.25}$

$\left\langle\varepsilon_{\mathrm{s}}\right\rangle=\sum_{i} f_{i} \varepsilon_{\mathrm{si}}$

$\langle\alpha\rangle=\sum_{i} f_{i} \alpha_{i}$ 
$\ln \left\langle z_{0}\right\rangle=\sum_{i} f_{i} \ln \left(z_{0_{i}}\right)$

$\langle d\rangle=\sum_{i} f_{i} d_{i}$

400

402

403

404

405

$40 B$

408

409

410

411

412

413

414

$41 B$

418

419

420

421

422

423

424

425

426

427

428

429

430

431

432

433

434

435

436

437

438

439

440

441

442

443

444

445

446

447

448

449

450

451

452

453

454

455

456

457 where $f_{i}$ is the fraction of the surface covered by the patch $i$ with obviously $\sum_{i} f_{i}=1 . T_{\mathrm{R} i}$ is the radiometric surface temperature over the patch $i$. In this study, $T_{\mathrm{R} i}$ was derived from measured soil and canopy temperatures weighted by the fractional area of vegetation (Ezzahar et al., 2007b; Norman et al., 1995) as follows:

$T_{\mathrm{R} i} \approx\left[f_{\mathrm{c}} T_{\mathrm{c}}^{4}+\left(1-f_{\mathrm{c}}\right) T_{\mathrm{s}}^{4}\right]^{1 / 4}$

where $f_{\mathrm{c}}$ is the cover fraction of olive trees, and $T_{\mathrm{s}}$ and $T_{\mathrm{c}}$ are the measured soil and canopy temperatures respectively, using two infrared thermometers.

$\varepsilon_{i}, \alpha_{i}, z_{0 i}$ and $d_{i}$ are the surface emissivity, the albedo, the roughness length and the displacement height for the patch $i$.

Finally, the grid-scale evapotranspiration derived from the spatial aggregation method (denoted as $\left\langle\mathrm{ET}_{\mathrm{Sim}}\right\rangle_{\mathrm{SA}}$ ) can be obtained as the residual term of the energy-bald Ace equation:

$\left\langle\mathrm{ET}_{\mathrm{Sim}}\right\rangle_{\mathrm{SA}}=\left\langle R_{\mathrm{n}}\right\rangle-\left\langle H_{\mathrm{Sim}}\right\rangle-\langle G\rangle$

Although this method seems very practical for estimating surface fluxes. However, as stated by Chehbouni et al. (2000a), it has a major limitation since its derivation is from semi-empirical relationships between the local and effective surface parameters are not always theoretically supported. In the regard, the relationship between model and observational variables (see Eq. (3)), which is established at patch scale, can introduce additional errors when extended to grid-scale. However, the finding of Chehbouni et al. (2000a, 2008a) seems to indicate that these errors have a limited impact on surface flux estimates. Nevertheless, establishing physically based relationships between model and observational variables at grid-scale is an ongoing research topic.

\subsubsection{Temporal aggregation}

Grid-scale evapotranspiration $(\langle E T\rangle)$ can be also determined using remote sensing data in conjunction with an energy-balance model. Practically, the sun-synchronous sensors are the most suitable for deriving $\langle\mathrm{ET}\rangle$ (French et al., 2005; Chehbouni et al., 2008a). However, these sensors provide only instantaneous values at the satellite overpass. These are of limited interest to water managers who are primarily focusing on daily values of $\langle E T\rangle$ (Bastiaanssen et al., 2000). Several methods have been proposed for extrapolating instantaneous ET to daily values. The simplest consist of relating daily ET to the instantaneous near surface vertical temperature gradient at midday (Jackson et al., 1977), or assuming the ET diurnal course is similar to that of solar irradiance, to be approximated by a sine function. However, due to their empirical character, both method accuracies are limited (Zhang and Lemeur, 1995). Another possibility is assuming a constant daytime evaporative fraction $(\mathrm{EF}(=\mathrm{ET} / \mathrm{AE}))$, to be used with daily available energy $\left(\mathrm{AE}\left(=R_{\mathrm{n}}-G\right)\right)$ for deriving daily ET (Sugita and Brutsaert, 1991; Gomez etal., 2005). The EF is defined as the ratio of ET to the available energy, AE. Recently, Hoedjes et al. (2008) have shown that assuming a constant daytime EF to derive accurate ET cannot be generalized to all surface conditions. Under dry conditions, the constant EF assumption seems to lead to reasonable results with regard to daily ET estimation. While under wet conditions, EF depicts a concave up shape with a pronounced decrease during early morning and a sharp increase during late afternoon (see Fig. 2 in Hoedjes et al., 2008). Furthermore, since the largest evaporative fluxes occur during these conditions, the use of a diurnal constant value of $\mathrm{EF}$ induces a large error in the calculation of ET.

To overcome this problem, Hoedjes et al. (2008) have proposed a new heuristic approach to parameterize the diurnal course of EF over homogeneous surfaces using the atmospheric parameters and

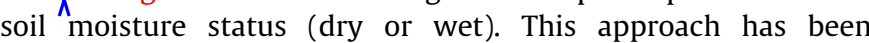
generalized by Chehbouni et al. (2008a) to a mixture of contrasted three fields (cotton, chickpea and wheat) in northern Mexico. In the current study, we applied the same method developed by Chehbouni et al. (2008a) to derive $\langle E F\rangle$ over a grid sparse olive tree canopy. Compared to earlier st Adies, our investigations were performed in difficult environmental conditions due to the type of vegetation (tall and sparse vegetation), and the irregular spacetime soil moisture pattern induced by the type of irrigation. On the grid-scale, the actual $\langle\mathrm{EF}\rangle$ diurnal course parameterized when accounting for both at ftospheric demand and soil moisture status is given by Chehbouni et al. (2008a):

$$
\left\langle\mathrm{EF}_{\mathrm{Sim}}^{\mathrm{ACT}}\right\rangle=\left\{\begin{array}{lll}
\left\langle\mathrm{EF}_{\mathrm{Sim}}\right\rangle r_{\mathrm{EF}}^{1130} & & \left\langle\beta^{1130}\right\rangle \leq 1.5 \\
\left\langle\mathrm{EF}_{\mathrm{Rem}}^{1130}\right\rangle & \text { for } & \\
\left\langle\beta^{1130}\right\rangle>1.5
\end{array}\right.
$$

$\left\langle\mathrm{EF}_{\mathrm{Sim}}\right\rangle$ is the EF diurnal course parameterized when accounting for atmospheric demand (i.e. global solar radiation $\left(R_{\mathrm{g}}\right)$ and relative humidity (RH)) only, which is formulated as:

$$
\left\langle\mathrm{EF}_{\mathrm{Sim}}\right\rangle=1.2-\left(0.4 \frac{R_{\mathrm{g}}}{1000}+0.5 \frac{\mathrm{RH}}{100}\right)
$$

$r_{\mathrm{EF}}^{1130}$ is a correction factor given by:

$r_{\mathrm{EF}}^{1130}=\frac{\left\langle\mathrm{EF}_{\mathrm{Rem}}^{1130}\right\rangle}{\left\langle\mathrm{EF}_{\mathrm{Sim}}^{1130}\right\rangle}$

where $\left\langle\mathrm{EF}_{\text {Sim }}^{1130}\right\rangle$ is $\left\langle\mathrm{EF}_{\mathrm{Sim}}\right\rangle$ at 11:30 UTC, and $\left\langle\mathrm{EF}_{\mathrm{Rem}}^{1130}\right\rangle$ is the EF estimated from remote sensing observations at 11:30 UTC calculated as:

$$
\left\langle\mathrm{EF}_{\mathrm{Rem}}^{1130}\right\rangle=\frac{(\langle\mathrm{AE}\rangle)_{\mathrm{Rem}}^{1130}-\left(\left\langle H_{\mathrm{Sim}}\right\rangle\right)_{\mathrm{Rem}}^{1130}}{(\langle\mathrm{AE}\rangle)_{\mathrm{Rem}}^{1130}},
$$

where $\left(\left\langle H_{\text {Sim }}\right\rangle\right)_{\operatorname{Rem}}^{1130}$ is the value of the sensible heat flux at 11:30. The latter was estimated from Eq. (11) using the effective radiometric surface temperature (Eq. (12)). $(\langle\mathrm{AE}\rangle)_{\mathrm{Rem}}^{1130}$ is the estimated available energy at 11:30 UTC calculated by combining Eqs. (9) and (10) using also the effective radiometric surface temperature.

$\left\langle\beta^{1130}\right\rangle$ is the value of the Bowen ratio $\left(\left(\left\langle H_{\text {Sim }}\right\rangle\right)_{\text {Rem }}^{1130} /(\langle\mathrm{AE}\rangle)_{\mathrm{Rem}}^{1130}-\left(\left\langle H_{\mathrm{Sim}}\right\rangle\right)_{\mathrm{Rem}}^{1130}\right)$ at 11:30 UTC, which is used to switch from a constant to a daily variable $\langle\mathrm{EF}\rangle$.

In this study, the time of 11:30 UTC Was chosen since it corresponds to the local time of overpass of the ASTER satellite (Hoedjes et al., 2008). When choosing the AVHRR overpass time over north-western Mexico, i.e. 14:00 UTC, Chehbouni et al. (2008a) have shown that this parameterization was also reasonable.

In addition to the parameterization of the $\langle E F\rangle$, retrieval of the diurnal course $\langle\mathrm{ET}\rangle$ requires also $\langle\mathrm{AE}\rangle$ over the diurnal cycle, which is not routinely available. Here again, the same heuristic approach developed by Chehbouni et al. (2008a) on the grid-scale, was used in this specific study. This approach combines the instantaneous remote sensing observations of $\mathrm{AE}\left((\langle\mathrm{AE}\rangle)_{\mathrm{Rem}}^{1130}\right)$ at 11:30 UTC with a function $\langle R\rangle$ involving the meteorological information which can be obtaifed from observation networks and/or weather forecasts 
to derive AE diurnal courses. The latter is expressed as:

$$
\left(\frac{(\langle\mathrm{AE}\rangle)^{t}}{(\langle\mathrm{AE}\rangle)_{\mathrm{Rem}}^{1130}}\right)=f\left(\frac{\langle R\rangle^{t}}{\left\langle R^{1130}\right\rangle}\right)
$$

where $R^{t}$ is a function given by:

$$
\left\langle R^{t}\right\rangle=(1-\langle\alpha\rangle) R_{\mathrm{g}}^{t}+\left\langle\varepsilon_{\mathrm{s}}\right\rangle \varepsilon_{\mathrm{a}}^{t} \sigma\left(T_{\mathrm{a}}^{t}\right)^{4}
$$

where $t$ is the time of the day, $f$ is the following 2 nd order function:

$$
f\left(\frac{\left\langle R^{t}\right\rangle}{\left\langle R^{1130}\right\rangle}\right)=a_{2}\left(\frac{\left\langle R^{t}\right\rangle}{\left\langle R^{1130}\right\rangle}\right)^{2}+a_{1}\left(\frac{\left\langle R^{t}\right\rangle}{\left\langle R^{1130}\right\rangle}\right)+a_{0}
$$

where $a_{0}, a_{1}$ and $a_{2}$ are empirical coefficients established by Hoedjes et al. (2008) as 0.48495, 1.15120 and 0.34285, respectively, when calibrating this function over a homogeneous olive orchard in Morocco. Using the same coefficients, Chehbouni et al. (2008a) have extended the AE parameterization with success to grid-scale. It is of important to notice that outgoing long wave radiation is purposely not introduced in Eq. (23). This was made to avoid the requirement for daily course of surface temperature which is not available at the appropriate space scale.

Finally, the grid-scale evapotranspiration $\left(\right.$ denoted, $\left._{\Lambda}\left\langle\mathrm{ET}_{\mathrm{sim}}\right\rangle_{\mathrm{TA}}\right)$ is obtained as follows:

$\left\langle\mathrm{ET}_{\mathrm{Sim}}\right\rangle_{\mathrm{TA}}=\left\langle\mathrm{EF}_{\mathrm{Sim}}^{\mathrm{ACT}}\right\rangle(\langle\mathrm{AE}\rangle)^{t}$

\section{Results and discussion}

In this study, only daytime observations have been considered, since the most important surface fluxes occur during this interval, and the behavior of the temperature structure parameter is not well known for stable conditions which can create greater uncertainty in the fluxes, especially over heterogeneous surfaces. Note that the half-hourly time scale is used in all analysis. This section will be organized as follows: firstly a comparison between the sensible heat fluxes derived from the LAS and those estimated using the Lhomme et al. (1994) model on the grid-scale. Secondly, we compare the LAS-derived diurnal course of the evapotranspiration and that estimated using spatial and temporal aggregation schemes on the grid-scale.

\subsection{Sensible heat fluxes}

Before evaluating the accuracy of the application of the Lhomme et al. (1994) model on the grid-scale, we first present

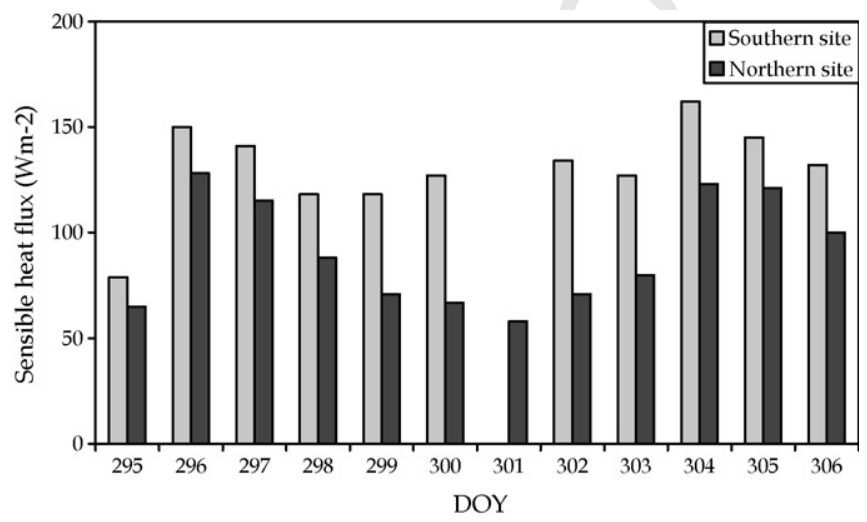

Fig. 4. Daily average daytime values of the sensible heat flux derived from the LAS over the northern and southern sites during the study period.

in Fig. 4 the daily average daytime values of the sensible heat flux derived from the LAS over both sites. The contrast between the two sites in terms of water availability (irrigation) can clearly be seen in this figure. Sensible heat flux values over the southern site are considerably higher than those over the northern site. The maximum difference between the values of $H$ was around $63 \mathrm{~W} \mathrm{~m}^{-2}$, seen on DOY 302.

At the patch scale, the Lhomme et al. (1994) model has been tested with success using the data collected over the southern site (Hoedjes et al., 2007, 2008). However, as far as we know such a study of the applicability of the Lhomme et al. (1994) model to the grid-scale has never been performed before. In this study, an effort has been made to apply this model over a heterogeneous grid which comprised the northern and southern sites using the aggregation rules. The simulated grid-scale sensible heat flux ( $\left.\left\langle H_{\text {Sim }}\right\rangle\right)$ was estimated using Eq. (11). Since satellite based surface temperature measurements were not available, ground-based surface temperature measured over each patch were used to construct grid-scale surface temperature using Eq. (12). Similarly, Eqs. (15) and (16) have been used to derive grid-scale displacement height and roughness length. Note that their patch scale values were derived as fraction of the vegetation height.

The effectiveness of this approach should have been validated by installing one scintillometer spanning the entire grid-scale. However, this could not be achieved easily for practical reasons since this unique scintillometer should have been installed much higher than the two LAS used in this study in order to avoid saturation.

To overcome this problem, Ezzahar et al. (2007a) developed a new approach to infer an aggregated structure parameter of the refractive index on the grid-scale $\left(\left\langle C_{n}^{2}\right\rangle\right)$ using the same data collected in the current study. This approach combines LAS patch scale measurements, meteorological data and aggregation schemes. For more details the reader can refer to Ezzahar et al. (2007a). It is worth mentioning that the obtained $\left\langle C_{n}^{2}\right\rangle$ behaved according to Monin-- Obukhov Similarity Theory. Then, this $\left\langle C_{n}^{2}\right\rangle$ was used to derive the grid-scale sensible heat flux $\left(\left\langle H_{\text {LAS }}\right\rangle\right)$ by applying MOST at the grid-scale. The accuracy of this approach has been investigated by comparing $\left\langle H_{\text {LAS }}\right\rangle$ to the area average of sensible heat flux measured by the ddy covariance systems which were installed on the meteorological towers (see Fig. 1). The result of this comparison showed a good agreement with a RMSD $=20.3 \mathrm{~W} \mathrm{~m}^{-2}$ and $R^{2}=0.89$ (Ezzahar et al., 2007a). Here, the values obtained for $\left\langle H_{\text {LAS }}\right\rangle$ in Ezzahar et al. (2007a) have been used to validate $\left\langle H_{\text {Sim }}\right\rangle$. $\left\langle H_{\text {LAS }}\right\rangle$ and $\left\langle H_{\text {Sim }}\right\rangle$. The RMSD is $30 \mathrm{~W} \mathrm{~m}^{-2}$ and the correlation coefficient and the slope associated with the linear regression

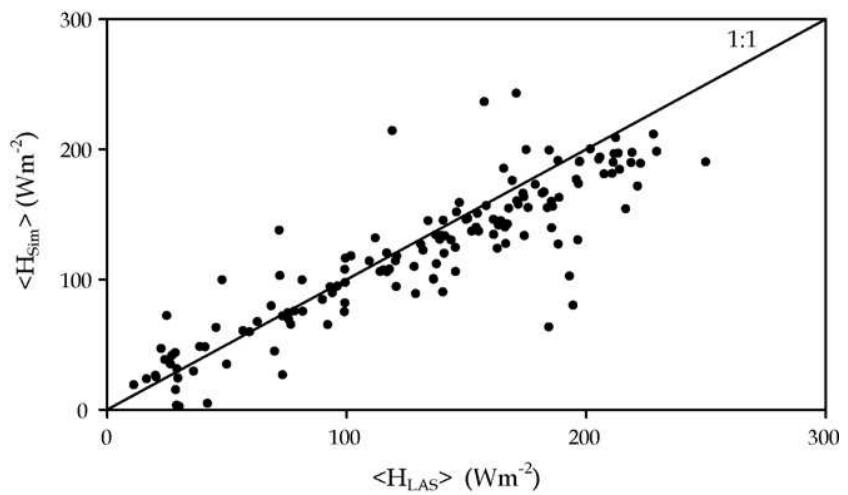

Fig. 5. Comparison between the sensible heat fluxes, $\left\langle\mathrm{H}_{\mathrm{Sim}}\right\rangle$ (using the Lhomme et al. (1994) model at grid-scale), and $\left\langle H_{\text {LAS }}\right\rangle$ (obtained by combining LAS patch scale measurements, meteorological data and an aggregation model, Ezzahar et al., 2007a). 

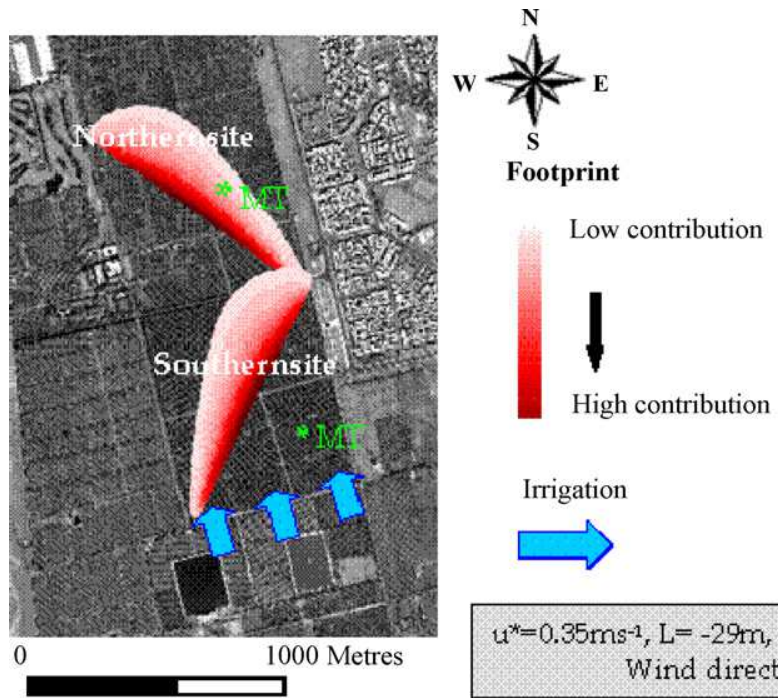

\section{Irrigation}

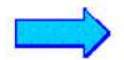

$\mathrm{u}^{*}=0.35 \mathrm{~ms}^{-1}, \mathrm{~L}=-29 \mathrm{~m}$, Sigma $\mathrm{v}=0.76 \mathrm{~ms}^{-1}$, Wind direction $=350^{\circ}$

Fig. 6. Footprint of the LAS, calculated using the footprint model of Horst and Weil (1994). The direction of irrigation is also shown.

forced to the origin were 0.76 and 0.90 , respectively. This result indicates that the aggregation schemes are not exact and errors are associated with some of the assumptions used to drive them. Additionally, some scatter is related to the footprint effect of the scintillometers (see Fig. 6). Nevertheless, considering the complexity of the study site, the obtained result is very encouraging. Consequently, it can be concluded albeit its simplicity, the Lhomme et al. (1994) model, can be considered a suitable model for estimating the sensible heat fluxes using the effective radiometric surface temperature over heterogeneous grids.

\subsection{Evapotranspiration}

\subsubsection{Spatial aggregation}

Before evaluating the accuracy of the evapotranspiration derived from the spatial aggregation, we compare first the gridscale available energy $\left(\left\langle\mathrm{AE}_{\mathrm{Sim}}\right\rangle\right)$ against the ground-based measurement (denoted $\left.\left\langle\mathrm{AE}_{\text {Meas }}\right\rangle\right)$ in Fig. 7. The $\left\langle\mathrm{AE}_{\mathrm{Sim}}\right\rangle$ was obtained by combining Eqs. (9) and (10). Here again, the estimation of the $\left\langle A E_{\text {Sim }}\right\rangle$ used the effective radiometric surface temperature Eq. (12)) through Eq. (9). The effective surface emissivity and albedo required for the estimation of the $\left\langle\mathrm{AE}_{\mathrm{Sim}}\right\rangle$, were derived from Eqs. (13) and (14). The $\left\langle\mathrm{AE}_{\mathrm{Meas}}\right\rangle$ was deflved as area-weighted averages of those measured over the southern and the northern

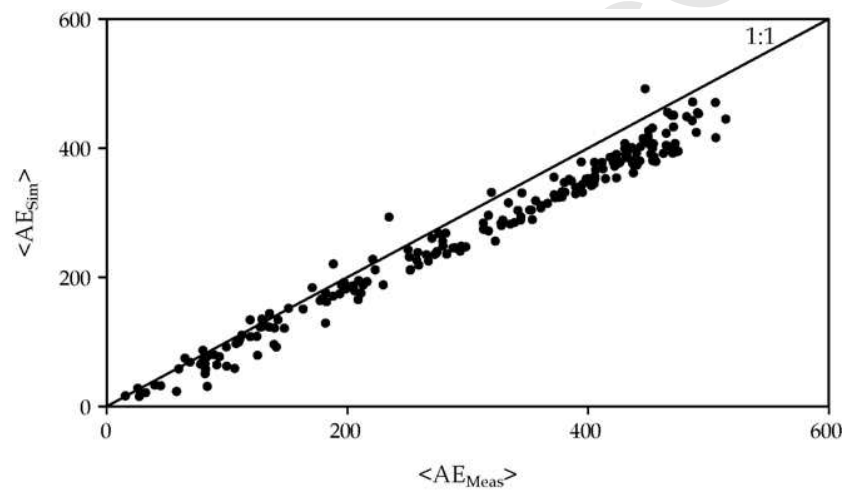

Fig. 7. Comparison between the estimated $\left(\left\langle A E_{S i m}\right\rangle\right.$, obtained using the spatial aggregation scheme, Eqs. (9) and (10)) and observed ( $\left\langle\mathrm{AE}_{\mathrm{Meas}}\right\rangle$, obtained as areaweighted averages of those measured over both sites) area-averaged available energy. sites. The correspondence between $\left\langle\mathrm{AE}_{\mathrm{Sim}}\right\rangle$ and $\left\langle\mathrm{AE}_{\mathrm{Meas}}\right\rangle$ was quite good. The RMSD value was $40 \mathrm{~W} \mathrm{~h}^{-2}$, and the linear regression forced to the origin yielded a 0.89 slope value and a 0.98 correlation coefficient. It should be noted that in this specific study, the atmospheric radiation was estimated using Brutsaert's formula without cloudiness correction; because the experiment period included few cloudless data. Except DOY 295, all days were sunny (see Fig. 2). Therefore, the use of Brutsaert's equation will not introduce significant error in the estimation of atmospheric radiation. However, there might be other sources of errors such as those related the uncertainly associated with the aggregation method which is purely of a semi-empirical nature, as well as those associated with the measurement of net radiation which ranges from $5 \%$ to $7 \%$ for instruments of the same manufacture and $10 \%$ to $15 \%$ between manufacturers (Field et al., 1992). It is also pôssible that some error compensation might have occurred which may explained the fact that difference between the estimated and measured available was less than expected even over homogeneous surfaces.

Using values of $\left\langle A E_{\text {Sim }}\right\rangle$ and $\left\langle H_{\text {Sim }}\right\rangle$ which were calculated using the effective radiometric surface temperature (see Eqs. (9)-(11)), the diurnal course of grid-scale evapotranspiration, $\left\langle\mathrm{ET}_{\mathrm{Sim}}\right\rangle_{\mathrm{SA}}$ was estimated as the residual term of the energy-balatice equation (Eq. (18)). $\left\langle^{\left.\mathrm{ET}_{\mathrm{Sim}}\right\rangle_{\mathrm{SA}} \text { was compared to the grid-scale evapotran- }}\right.$

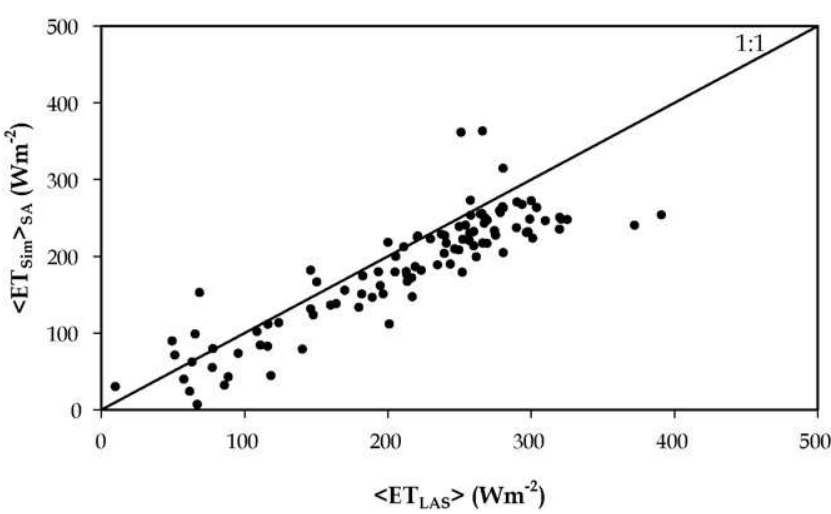

Fig. 8. Comparison between $\left\langle\mathrm{ET}_{\mathrm{Sim}}\right\rangle_{\mathrm{SA}}$ (estimated using the spatial aggregation scheme) and $\left\langle\mathrm{ET}_{\mathrm{LAS}}\right\rangle$ (obtained form the LAS as the difference between the $\left\langle\mathrm{AE}_{\text {Meas }}\right\rangle$

Please cite this article in press as: Ezzahar, J., Chehbouni, A., The use of scintillometry for validating aggregation schemes over heterogeneous grids. Agric. Forest Meteorol. (2009), doi:10.1016/j.agrformet.2009.09.004 
spiration $\left(\left\langle\mathrm{ET}_{\mathrm{LAS}}\right\rangle\right)$ derived from the LAS as the difference between the $\left\langle A E_{\text {Meas }}\right\rangle$ and $\left\langle H_{\text {LAS }}\right\rangle$ in Fig. 8. The RMSD between $\left\langle E_{\text {Sim }}\right\rangle_{S A}$ and

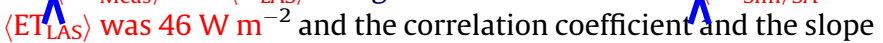
associated with the linear regression forced to the origin were 0.78 and 0.87 , respectively. This confirms the results reported by several authors where the potential of the LAS to derive accurate evapotranspiration has been demonstrated (Ezzahar et al., 2007b, 2009; Chehbouni et al., 2000b, in press; Hemakumara et al., 2003; Hoedjes et al., 2002). It should be noted that the problem of closure of the energy balance has no big effect on the results, because both approaches forced the energy-balance closure. Such discrepancy can be explained by the combination of two factors. First, the error associated to the impact of the footprint. Second, since the ET is obtained as the residual term of the energy-balance equation, any difference between measured and $\wedge$ estimated available energy and sensible heat flux is directly translated into error in the estimated ET. However, despite the observed scatter, the correspondence between $\left\langle E_{\text {Sim }}\right\rangle_{S A}$ and $\left\langle\mathrm{ET}_{\text {LAS }}\right\rangle$ is acceptable considering the difficulty $A$ estimating grid-scale latent heat flux over such complex grid. Finally, it can be concluded that the spatial aggregation procedure yielded reasonable grid surface fluxes estimates.

\subsubsection{Temporal aggregation}

In this section an effort has been made to extend the heuristic approach which consists of extrapolating instantaneous values to daily ones proposed by Hoedjes et al. (2008) over a homogeneous patch to a heterogeneous grid (tall and sparse vegetation, irrigation method employed). Before obtaining the grid-scale evapotranspiration using the temporal aggregation, the grid-scale of available energy $\left(\left\langle\mathrm{AE}_{\mathrm{Sim}}\right\rangle\right)$ estimated using Eq. (22), was compared to the ground-based measurements $\left(\left\langle\mathrm{AE}_{\text {Meas }}\right\rangle\right)$ in Fig. 9. The correspondence between $\left\langle A E_{\text {Sim }}\right\rangle$ and $\left\langle A E_{\text {Meas }}\right\rangle$ was quite good. The RMSD value was $47 \mathrm{~W} \mathrm{~m}$, and the linear regression forced to the origin yielded a 0.90 slope value and a 0.91 correlation coefficient. By comparing these results with those obtained when we used the spatial aggregation, it can be seen that in addition to the error related to the spatial aggregation, the use of the temporal aggregation generates an added extra error in the estimation of $\langle\mathrm{AE}\rangle$ (about 21\%). However, considering the complexity of the grid, the footprint effect and the error associated with the assumptions used to drive aggregation rules, it can be concluded that the proposed heuristic approach leads to reasonable estimates of the diurnal course area average available energy. The results of this study confirm and generalize the findings of Hoedjes et al. (2008) who established thîs heuristic approach on the southern site which was one of the two patches of our grid-scale study as well as those established by Chehbouni et al. (2008a) over short vegetation.

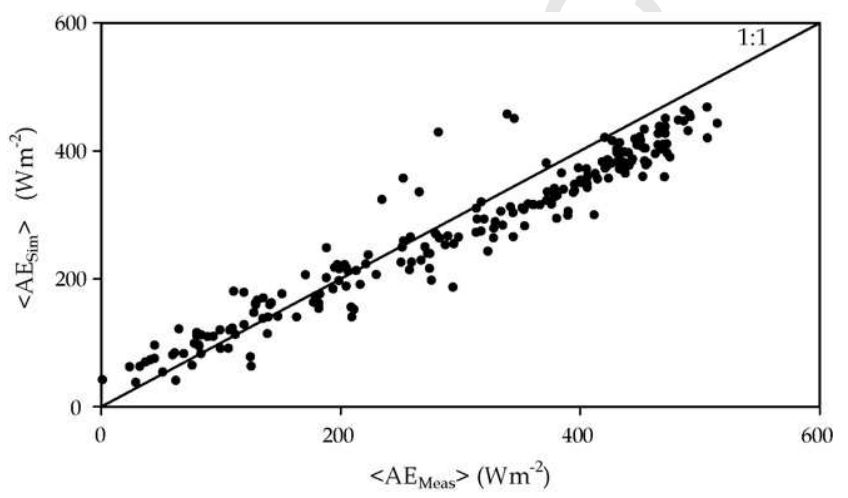

Fig. 9. Comparison between the estimated $\left(\left\langle\mathrm{AE}_{\mathrm{Sim}}\right\rangle\right.$, obtained using the temporal aggregation scheme (Eq. (22))) and observed ( $\left\langle\mathrm{AE}_{\text {Meas }}\right\rangle$, obtained as area-weighted averages of those measured over both sites) area-averaged available energy.

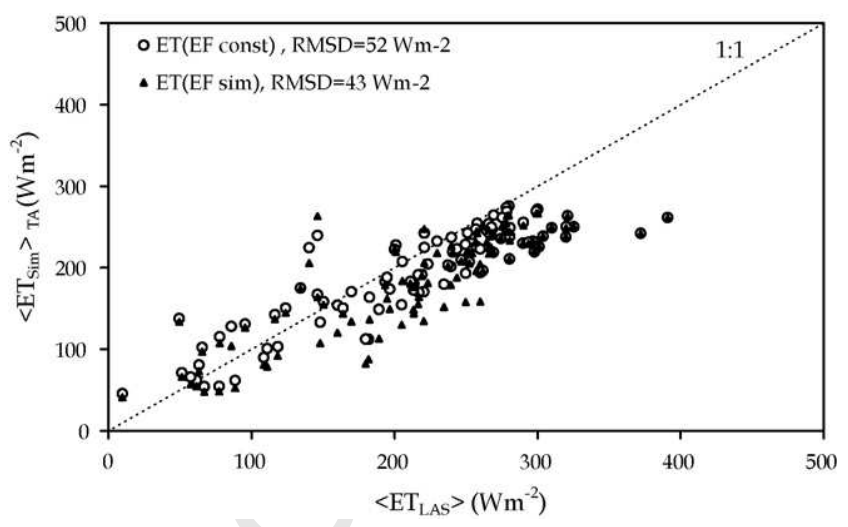

Fig. 10. Comparison between $\left\langle\mathrm{ET}_{\mathrm{Sim}}\right\rangle_{\mathrm{TA}}$ (estimated using the temporal aggregation scheme through Eqs. (19)-(25) ) and $\left\langle\mathrm{ET}_{\text {LAS }}\right\rangle$ (obtained form the LAS as the difference between the $\left\langle\mathrm{AE}_{\mathrm{Meas}}\right\rangle$ and $\left.\left\langle\mathrm{H}_{\mathrm{LAS}}\right\rangle\right)$. AAso included is the grid-scale evapotranspiration calculated by considering a constant diurnal evaporative fraction (EF) equal to that at 11:30 UTC $\left(\mathrm{EF}_{1130}\right)$.

Finally, the diurnal course of the grid-scale evapotranspiration, $\left\langle\mathrm{ET}_{\text {sim }}\right\rangle_{\mathrm{TA}}$, was retrieved using Eqs. (19)-(25). Fig. 10 displays the $\checkmark$ alidation of these $\left\langle\mathrm{ET}_{\mathrm{Sim}}\right\rangle_{\mathrm{TA}}$ retrievals, against values derived from the LAS $\left(\left\langle\mathrm{ET}_{\mathrm{LAS}}\right\rangle\right)$. Also included is the grid-scale evapotranspiration calculated by considering a constant diurnal evaporative fraction (EF) equal to that at $11 \mathrm{H} 30\left(\mathrm{EF}_{1130}\right)$. It can be clearly seen that taking into account the diurnal variation of EF significantly improves $\left\langle\mathrm{ET}_{\text {sim }}\right\rangle_{\mathrm{TA}}$ retrieval. RMSD between $\left\langle\mathrm{ET}_{\text {sim }}\right\rangle_{\mathrm{TA}}$ and $\left\langle\mathrm{ET}_{\mathrm{LAS}}\right\rangle$ was $43 \mathrm{~W} \mathrm{~m}^{-2}$, the relative error was $19 \%$ and the slope was 0.88 , as compared to $52 \mathrm{~W} \mathrm{~m}^{-2}, 27 \%$ and 0.82 , respectively when using a constant EF. These results corroborated with those established by Hoedjes et al. (2008) and Chehbouni et al. (2008a). Additionally, by properly taking into account the effect of the grid heterogeneity due to both vegetation and soil moisture variations along the grid and the error associated to the application of the aggregation rules, the agreement between the $\left\langle\mathrm{ET}_{\mathrm{sim}}\right\rangle_{\mathrm{TA}}$ and $\left\langle\mathrm{ET}_{\mathrm{LAS}}\right\rangle$ is considered to be acceptable.

In general, as for the spatial aggregation scheme, the temporal aggregation method can be considered suitable for practical purposes. Indeed, the spatial aggregation needs the diurnal courses of the radiometric surface temperature for calculating the sensible heat fluxes and the available energy. However, this variable cannot be obtained using remote sensing technique at the required scale for irrigation management purposes (a few hundred meters resolution). Geostationary sensors can provide the diurnal courses of spatially radiometric surface temperature with temporal sampling from $15 \mathrm{~min}$ to $1 \mathrm{~h}$, but their spatial resolution is very coarse. The advantage of combining spatial and temporal aggregation schemes is to be able to estimate daily value of ET at the grid-scale using a single value of surface temperature at the satellite overpass time.

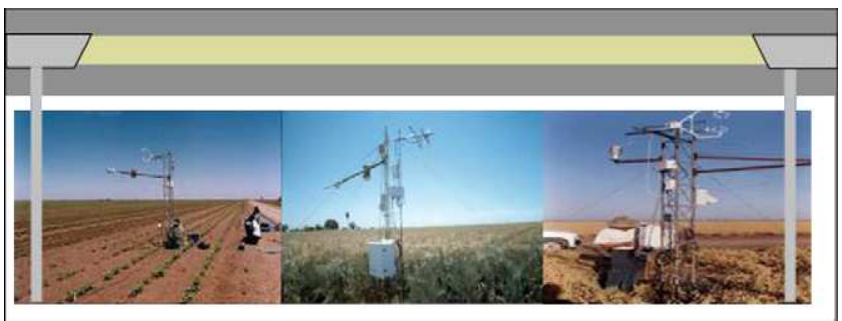

Fig. 11. Experimental design for the Yaqui valley experiment (Chehbouni et al., 2008a, in press).
684

685

686

687

688

689

690

691

692

693

694

695

696

697

698

699

700

701

702 703 704 705 706 707 708 709 710 711 712 713

Please cite this article in press as: Ezzahar, J., Chehbouni, A., The use of scintillometry for validating aggregation schemes over heterogeneous grids. Agric. Forest Meteorol. (2009), doi:10.1016/j.agrformet.2009.09.004 


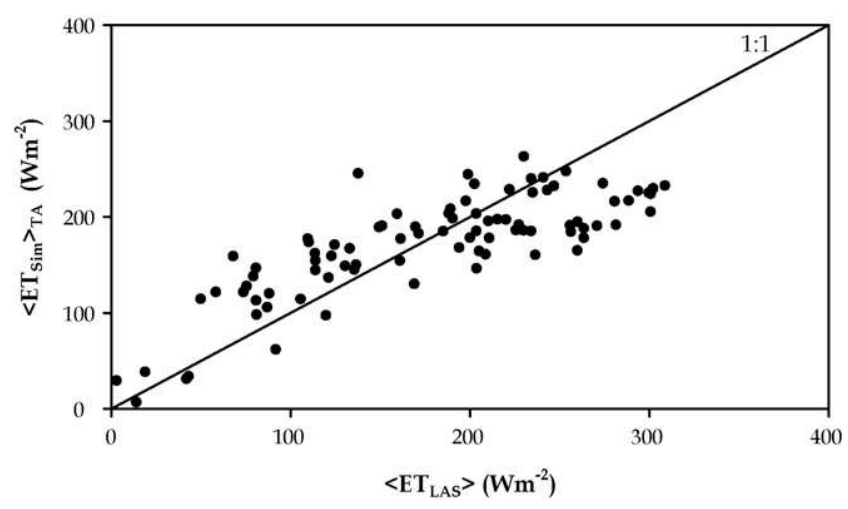

Fig. 12. Comparison between $\left\langle\mathrm{ET}_{\mathrm{Sim}}\right\rangle_{\mathrm{TA}}$ (estimated using the temporal aggregation scheme (Chehbouni et al., 2008a)) and $\left\langle\mathrm{ET}_{\mathrm{LAS}}\right\rangle$ (obtained form the LAS, Chehbouni et al., in press).

To further assess the performance of the developed combination of temporal and spatial aggregation methods, a second dataset collected in northern Mexico (Chehbouni et al., 2008a, in press) was used. The grid consisted of three adjacent fields: cotton, chickpea and wheat. The three fields with eddy covariance flux towers are shown in Fig. 11. Both studies used the same data. Here, we briefly recall the objectives of these studies. In Chehbouni et al. (2008a), the temporal aggregation scheme for deriving diurnal course of $\left\langle\mathrm{ET}_{\text {sim }}\right\rangle_{\mathrm{TA}}$ was tested with success over the three fields by comparing the $\left\langle\mathrm{ET}_{\mathrm{Sim}}\right\rangle_{\mathrm{TA}}$ retrievals to those measured by the eddy covariance systems. This was achieved by using the same temporal aggregation scheme used in this study (Eqs. (19)-(25)). The study of Chehbouni et al. (in press) aimed to assess the potential and the limitations of the CAS in inferring path average of the sensible ( $\left.\left\langle H_{\mathrm{LAS}}\right\rangle\right)$ and latent $\left(\left\langle\mathrm{ET}_{\mathrm{LAS}}\right\rangle\right)$ fluxes over the three fields by Comparing the LAS fluxes to those measured by the eddy covariance systems.

Fig. 12 presents the comparison of $\left\langle\mathrm{ET}_{\mathrm{sim}}\right\rangle_{\mathrm{TA}}$ (derived in Chehbouni et al. (2008a)) with $\left\langle\mathrm{ET}_{\mathrm{LAS}}\right\rangle$ (derived in Chehbouni et al., in press). The statistical results of this comparison showed that the RMSD was about $48 \mathrm{~W} \mathrm{~m}^{-2}$ and the correlation coefficient and the slope associated with the linear regression forced to the origin were 0.90 and 0.65 , respectively. Comparing these results with those obtained in the current study, it can be concluded that the proposed approach can be used with success in different environmental conditions. The results are an important step toward developing the remote sensing algorithms for better estimation of the evapotranspiration on a large scale relying on the use of the scintillometry. Additional investigation using data collected over a range of surface type combinations are required to generalize and confirm our finding, and more importantly, future research should be directed towards building robust relationships between model and observational variables directly at the gridscale.

\section{Conclusions}

Comparisons of grid-scale evapotranspiration derived from the scintillometer with those estimated from the spatial and temporal aggregation schemes, under difficult environment conditions (sparseness of vegetation and heterogeneity in terms of soil moisture pattern induced by the "flood irrigation" method), showed an acceptable result using data collected in the central of Morocco. Additionally, the temporal aggregation scheme has been tested with success over a heterogeneous grid in a semi-arid region in northern Mexico. This finding confirms and generalizes the consistency of the aggregation schemes for accurate estimates of the evapotranspiration over heterogeneous grids. However, it is worth noting that the aggregation algorithms presented here have some limitations. The method to establish relationships between the local and effective surface parameters is purely of a semiempirical nature which is not universal. Additionally this method uses local measurements of surface temperature; albedo and solar radiation which were assumed to be representative of the individual site. This assumption can certainly lead to some errors since the heterogeneity is also encountered at the field or patch scale. Future research should be thus directed towards building robust physical relationships between the local and effective surface parameters as well as testing it using remotely sensed data, which provide spatial distribution of surface temperature, albedo and solar radiation.

\section{Acknowledgements}

This study has been funded by IRD, additional funding was provided by E.U. through PLEIADES project. We are very grateful to all SUDMED research and technical staff for their help during the course of the experiment. The authors wish to thank Pr. Ian Timms for his help in the correct english expression of the manuscript. The authors are grateful to the two anonymous reviewers and guest editor for their insightful comments.

\section{Appendix A}

\section{A.1. Surface fluxes using scintillometry}

The LAS is a device that provides measurements of the variation in the refractive index of air caused by atmospheric turbulence. This instrument consists of a transmitter and a receiver, both with an aperture diameter of $0.15 \mathrm{~m}$, set up at a separation distance (or path length) ranging from 250 to $5000 \mathrm{~m}$. The transmitter emits electromagnetic radiation, which is scattered by the turbulent atmosphere, and the resulting variations in signal intensity (scintillations) are recorded by a receiver comprising an identical mirror and a photodiode detector. The intensity fluctuations are related to the path average structure parameter of the refractive index of air, $C_{n}^{2}$. The scintillations are primarily the result of fluctuations in air temperature and humidity. Strictly speaking, the measured $C_{n}^{2}$ is related to the structure parameters of temperature $C_{T}^{2}$, of humidity $C_{q}^{2}$, and the covariant term $C_{T q}$. For electromagnetic waves in the visible and nearinfrared region, however, humidity related scintillations are much smaller than temperature related scintillations. Wesely (1976), and more recently Moene (2003), have shown that for a LAS operating at a near-infrared wavelength, we can derive the structure parameter of temperature $C_{T}^{2}$ from $C_{n}^{2}$ using:

$C_{T}^{2}=C_{n}^{2}\left(\frac{T_{\mathrm{a}}^{2}}{-0.78 \times 10^{-6} p}\right)^{2}\left(1+\frac{0.03}{\beta}\right)^{-2}$

where $T_{\mathrm{a}}$ is the air temperature $(\mathrm{K}), p$ is atmospheric pressure ( $\mathrm{Pa}$ ) and $\beta$ is the Bowen ratio. The factor involving the Bowen ratio is the correction term for the influence of humidity fluctuations.

Using Monin-Obukhov Similarity Theory (MOST), the sensible heat flux $\left(H_{\text {LAS }}\right)$ can be obtained from $C_{T}^{2}$ and additional wind speed data through the following dimensionless relationship:

$\frac{C_{T}^{2}\left(z_{\mathrm{LAS}}-d\right)^{2 / 3}}{T_{*}^{2}}=f_{T}\left(\frac{z_{\mathrm{LAS}}-d}{L}\right)=c_{T 1}\left(1-c_{T 2} \frac{z_{\mathrm{LAS}}-d}{L}\right)^{-2 / 3}$

where $L$ is the Obukhov length $(\mathrm{m})\left(L=\rho c_{p} T_{\mathrm{a}} u_{*}^{3} / k g H_{\mathrm{LAS}}\right)$, and $T_{*}$ is the temperature scale $\left(T_{*}=\frac{-H_{\mathrm{LAS}}}{\rho c_{p} u_{*}}\right)$. The friction velocity $\left(u_{*}\right)$ is
784 
expressed as:

$u_{*}=k u\left[\operatorname{Ln}\left(\frac{\left(z_{\mathrm{LAS}}-d\right)}{z_{0}}\right)-\psi \frac{\left(\left(z_{\mathrm{LAS}}-d\right)\right.}{L}\right]^{-1}$

819

816

817

818

819

820

821

822

823

824

825

826

827

828

829

where $z_{\text {LAS }}$ is the effective height of the LAS above the surface, $\psi$ is the integrated stability function (Panofsky and Dutton, 1984), $d$ is the displacement height and $z_{0}$ is the roughness length, $k$ is the von Karman constant, $g$ is the gravitational acceleration, $\rho$ is the density of air and $c_{p}$ is the specific heat of air at constant pressure. Here, $d$ and $z_{0}$ were calculated as a function of the vegetation height (Ezzahar et al., 2007a,b). During the iteration procedure, the Bowen ratio is evaluated using the $H_{\text {LAS }}$, measured net radiation $\left(R_{\mathrm{n}}\right)$ and measured soil heat flux $(G)\left[\beta=\left(H_{\mathrm{LAS}} /\left(R_{\mathrm{n}}-G-H_{\mathrm{LAS}}\right)\right)\right]$. In this study we will confine ourselves to unstable conditions and will use the MOST relationship $f_{T}$ in Eq. (2) given by De Bruin et al. (1993).

Finally, the ET from the LAS can be derived by imposing the energy-balance closure assumption (Chehbouni et al., 2000b, in press; Ezzahar et al., 2007b, 2009; Hemakumara et al., 2003; Hoedjes et al., 2002).

\section{References}

Q2 Angstrom, A., 1918. A study of the net radiation of the atmosphere. Smithson. Inst. Coll. 65, 159-161.

Arain, A.M., Michaud, J., Shuttleworth, W.J., 1996. Testing of vegetation parameter aggregation rules applicable to the biosphere-atmosphere transfer scheme (BATS) and the FIFE site. Journal of Hydrology 177 (1-2), 1-22.

Asanuma, J., Lemoto, K., 2006. Measurements of regional sensible heat flux over Mongolian grassland using large aperture scintillometer. Journal of Hydrology 333, 58-67.

Bastiaanssen, W.G.M., Molden, D.J., Makin, I.W., 2000. Remote sensing for irrigated agriculture: examples from research and possible applications. Agricultural Water Management 46, 137-155.

Blyth, E.M., Harding, R.J., 1995. Application of aggregation models to surface heatflux from the Sahelian Tiger Bush. Agricultural and Forest Meteorology 72 (3-4) 213-235.

Braden, H., 1995. Energy fluxes from heterogeneous terrain-averaging input parameters of the Penman-Monteith Formula. Agricultural and Forest Meteorology 75 (1-3), 121-133.

Brunt, D., 1932. Notes on radiation in the atmosphere. Quarterly Journal of the Royal Meteorological Society 58, 389-418.

Brutsaert, W., 1975. On a derivable formula for long-wave radiation from clear skies. Water Resources Research 11, 742-744.

Brutsaert, W., 1982. Evaporation into the Atmosphere. Reidel, Dordrecht, 299 pp.

Chehbouni, A., Njoku, E.G., Lhomme, J.P., Kerr, Y.H., 1995. Approaches for averaging surface parameters and fluxes over heterogeneous terrain. Journal of Climate 8 (5), 1386-1393.

Chehbouni, A., Kerr, Y.H., Watts, C., Hartogensis, O., Goodrich, D.C., Scott, R. Schieldge, J., Lee, K., Shuttleworth, W.J., Dedieu, G., De Bruin, H.A.R., 1999. Estimation of area-average sensible heat flux using a large aperture scintillometer. Water Resources Research 35, 2505-2512.

Chehbouni, A., Watts, C., Kerr, Y.H., Dedîeu, G., Rodriguez, J.-C., Santiago, F., Cayrol, P., Boulet, G., Goodrich, D.C., [144_TD\$DIFF]2000a. Methods to aggregate turbulent fluxes over heterogeneous surfaces: application to SALSA data set in Mexico. Agricultural and Forest Meteorology 105, 133-144.

Chehbouni, A., Watts, C., Lagouarde, J.P., Kerr, Y.H., Rodriguez, J.C., Bonnnefond, J.M., Santiago, F., Dedieu, G., Goodrich, D.C., Unkrich, C., 2000b. Estimation of heat fluxes and momentum fluxes over complex terrain using a large aperture scintillometer. Agricultural and Forest Meteorology 105, 215-226.

Chehbouni, A., Hoedjes, J.C.B., Rodriquez, J.C., Watts, C.J., Garatuza, J., Jacob, F., Kerr, Y.H., 2008a. Using remotely sensed data to estimate area-averaged daily surface over a semi-arid mixed agriculture land. Agricultural and Forest Meteorology 149, 330-342.

Q3 Chehbouni, A., Ezzahar, J., Watts, C., Rodríguez, J.C., Garatuza-Payan, J. Estimating area-averaged surface fluxes over contrasted agricultural patchwork in a semiarid region. In: Hill J., Röder A. (Eds.), Advances in Remote Sensing an Geoinformation Procêssing for Land Degradation Assessment. Taylor and Francis, in press.

Chehbouni, A., Escadafal, R., Boulet, G., Duchemin, B., Simonneaux, V., Dedieu, G., Mougenot, B., Khabba, S., Kharrou, H., Maisongrande, Ph., Merlin, O., Chaponnière, A., Ezzahar, J., Erraki, S., Hoedjes, J., Hadria, R., Abourida, A., Cheggour, A., Raibi, F., Boudhar, A., Benhadj, I., Hanich, L., Benkaddour, A., Guemouria, N., Chehbouni, Ah., Olioso, A., Jacob, F., Sobrino, J., [150_TD\$DIFF]2008b. Integrated modelling and remote sensing approach for hydrological study in arid and semi-arid regions: the SUDMED Program. International Journal of Remote Sensing 29, 5161-5181, doi:10.1080/01431160802036417.
Choudhury, B.J., Monteith, J.L., 1988. A four-layer model for the heat budget of homogeneous land surfaces. Quarterly Journal of the Royal Meteorological Society $114,373-398$.

Choudhury, B.J., 1987. Relationships between vegetation indices, radiation absorption, and net photosynthesis evaluated by a sensitivity analysis. Remote Sensing of Environment 22, 209-233.

Crawford, T.M., Stensrud, D.J., Carlson, T.N., Capehart, W.J., 2000. Using a soil hydrology model to obtain regionally averaged soil moisture values. Journal of Hydrometeorology 1, 353-363.

De Bruin, H.A.R., Kohsiek, W., van den Hurk, B.J.J.M., 1993. A verification of some methods to determine the fluxes of momentum, sensible heat and water vapour using standard deviation and structure parameter of scalar meteorological quantities. Boundary Layer Meteorology 63, 231-257.

Duarte, H.F., Dias, N.L., Maggiotto, S.R., 2006. Assessing daytime downward longwave radiation estimates for clear and cloudy skies in Southern Brazil. Agricultural and forest meteorology 139, 171-181.

Er-Raki, S., Chehbouni, A., Hoedjes, J., Ezzahar, J., Duchemin, B., Jacob, F., 2008. Assimilation of ASTER based ET estimates in FAO 56 model over olive orchards in a semi-arid region. Agricultural Water Management 95, 309-321.

Ezzahar, J., Chehbouni, A., Hoedjes, J.C.B., Chehbouni, Ah., 2007a. On the application of scintillometry over heterogeneous surfaces. Journal of Hydrology 34, 493501.

Ezzahar, J., Chehbouni, A., Hoedjes, J.C.B., Er-raki, S., Chehbouni, Ah., Bonnefond, J.M. De Bruin, H.A.R., 2007b. The use of the scintillation technique for estimating and monitoring water consumption of olîve orchards in a semi arid region. Agriculture Water Management 89, 173-184.

Ezzahar, J., Chehbouni, A., Hoedjes, J., Ramier, D., Boulain, N., Boubkraoui, S., Cappelaere, B., Descroix, L., Mougenot, B., Timouk, F., 2009. Combining scintillometer and an aggregation scheme to estimate area-averaged latent heat flux during AMMA Experiment. Journal of Hydrology, doi:10.1016/j.jhydrol.2009.01.010,

Field, R.T., Fritschen, L.J., Kanemasu, E.T., Smith, E.A., Stewart, J.B., Verma, S.B., Kustas, W.P., 1992. Calibration, comparison, and correction of net radiation instruments used during FIFE. ^ournal of Geophysical Research 97 (D17), $18,681-18,695$.

French, A.N., Jacob, F., Anderson, M.C., Kustas, W.P., Timmermans, W., Gieske, A., Su, B., Su, H., McCabe, M.F., Li, F., Prueger, J., Brunsell, N., 2005. Surface energy fluxes with the Advanced Spaceborne Thermal Emission and Reflection radiometer (ASTER) at the Iowa 2002 SMACEX site (USA). Remote Sensing of Environment 99, 55-65.

Gomez, M., Sobrino, J., Olioso, A., Jacob, F., 2005. Retrieval of evapotranspiration over the Alpilles test site using PolDER and thermal camera data. Remote Sensing of Environment 96, 399-408.

Hemakumara, H.M., Chandrapala, L., Moene, A.F., 2003. Evapotranspiration fluxes over mixed vegetation areas measured from large aperture scintillometer. Agricultural Water Management 58, 109-122.

Hoedjes, J.C.B., Zuurbier, R.M., Watts, C.J., 2002. Large aperture scintillometer used over a homogeneous irrigated area, partly affected by regional advection. Boundary Layer Meteorology 105, 99-117.

Hoedjes, J.C.B., Chehbouni, A., Ezzahar, J., Escadafal, R., De Bruin, H.A.R., 2007. Comparison of large aperture scintillometer and eddy covariance measurements: can thêrmal infrared data be used to capture footprint induced differences? Journal of Hydrometeorology 8, 144-159.

Hoedjes, J.C.B., Chehbouni, A., Jacob, F., Ezzahar, J., Boulet, G., 2008. Deriving daily evapotranspiration from remotely sensed instantaneous evaporative fraction over olive orchard in semi-arid Morocco. Journal of Hydrology 354, 53-64.

Horst, T.W., Weil, J.C., 1994. How far is far enough? The fetch requirements for micrometeorological measurement of surface fluxes. Journal of Atmospheric and Oceanic Technology 11, 1018-1025

Humes, K.S., Kustas, W.P., Moran, M.S., 1994. Use of remote sensing and reference site measurements to estimate instantaneous surface energy balance components over a semiarid rangeland watershed. Water Resources Research 30, 1363-1373.

Kleissl, J., Gomez, J., Hong, S.-H., Hendrickx, J.M.H., Rahn, T., Defoor, W.L., 2006. Large aperture scintillometer intercomparison study. Boundary Layer Meteorology $128,133-150$

Idso, S.B., 1981. A set of equations for full spectrum and 8 to $14 \mathrm{~mm}$ and 10.5 to $12.5 \mathrm{~mm}$ thermal radiation from cloudless skies. Water Resources Research 17, 295-304.

Jackson, R.D., Reginato, R.J., Idso, S.B., 1977. Wheat canopy temperature: a practical tool for evaluating water requirements. Water Resources Research 13, 651-656.

Jones, H.G., Archer, N., Rotenberg, E., Casa, R., 2003. Radiation measurement for plant ecophysiology. Journal of Experimental Botany 54, 879-889.

Kustas, W.P., Daughtry, C.S.T., van Oevelen, P.J., 1993. Analytical treatment of the relationships between soil heat flux/net radiation ratio and vegetation indices. Remote Sensing of Environment 46, 319-330.

Kustas, W.P., Goodrich, D.C., 1994. Preface to special section on Monsoon'90. Water Resources Research 30, 1211-1225.

Kustas, W.P., Norman, J.M., 2000. Evaluating the effects of subpixel heterogeneity on pixel average fluxes. Remote Sensing of Environment 74, 327-342.

Kustas, W.P., Norman, J.M., 1999. Evaluation of soil and vegetation heat flux predictions using a simple two-source model with radiometric temperatures for partial canopy cover. Agricultural and Forest Meteorology 94, 13-29.

Kustas, W.P., Norman, J.M., Schmugge, T.J., Anderson, M.C., 2004. Mapping surface energy fluxes with radiometric temperature. In: Quattrochi, D.A., Luvall, J.C. 
(Eds.), Thermal Remote Sensing in Land Surface Processes. CRC Press, Boca Raton, Florida, pp. 205-253.

Kustas, W.P., Diak, G.R., Norman, J.M., 2001. Time difference methods for monitoring regional scale heat fluxes with remote sensing. In: Lakshmi, V., Albertson, J., Schaake, J. (Eds.), Observations and Modeling of The Land Surface Hydrological Processes. American Geophysical Union Water Science and Application Series, 3. pp. 15-29.

Kustas, W.P., Norman, J.M., 1996. Use of remote sensing for evapotranspiration monitoring over land surfaces. Hydrological Sciences 41, 495-516.

Lagouarde, J.P., Bonnefond, J.M., Kerr, Y.H., McAneney, K.J., Irvine, M., 2002. Integrated sensible heat flux measurements of a two-surface composite landscape using scintillometry. Boundary Layer Meteorology 105, 5-35.

Lhomme, J.-P., Monteny, B., Amadou, M., 1994. Estimating sensible heat flux from radiometric temperature over sparse millet. Agricultural and Forest Meteorology 68, 77-91.

Marx, A., Kunstmann, H., Schuttemeyer, D., Moene, A.F., 2008. Uncertainty analysis for satellite derived sensible heat fluxes and scintillometer measurements over savannah environment and comparison to mesoscale meteorological simulation results. Agricultural and Forest Meteorology 148, 656-667.

McCabe, M.F., Wood, E.F., 2006. Scale influences on the remote estimation of evapotranspiration using multiple satellite sensors. Remote Sensing of Environment 105 (4), 271-285.

Mecikalski, J.R., Diak, G.R., Anderson, M.C., Norman, J.M., 1999. Estimating fluxes on continental scales using remotely sensed data in an atmospheric-land exchange model. Journal of Applied Meteorology 38, 1352-1369.

Monteith, J.L., Unsworth, M.H., 1990. Principles of Environmental Physics. Edward Arnold, London, $291 \mathrm{p}$.

4 Merlin, O., Chehbouní, A., 2004. Different approaches in estimating heat flux using dual angle observations of radiative surface temperature. International Journal of Remote Sensing 25 (15) 275-289.

Moene, A.F., 2003. Effects of water vapour on the structure parameter of the refractive index for near-infrared radiation. Boundary Layer Meteorology 107, 635-653.

Moran, M.S., Humes, K.S., Pinter, P.J., 1997. The scaling characteristics of remotelysensed variables for sparsely vegetated heterogeneous landscapes. Journal of Hydrology 190 (3-4), 337-362.

Noilhan, J., Lacarrere, P., Dolman, A.J., Blyth, E.M., 1997. Defining area-average parameters in meteorological models for land surfaces with mesoscale heterogeneity. Journal of Hydrology 190 (3-4), 302-316.

Norman, J.M., Kustas, W.P., Humes, K.S., 1995. A two-source approach for estimating soil and vegetation energy fluxes from observations of directional radiometric surface temperature. Agriculture and Forest Meteorology 77, 263-293.

Norman, J.M., Kustas, J., Prueger, H., Diak, G.R., 2000. Surface flux estimation using radiometric temperature: a dual-temperature-difference method to minimize measurement errors. Watêr Resources Research 36, 2263-2274.
Norman, J.M., Anderson, M.C., Kustas, W.P., French, A.N., Mecikalski, J.R., Torn, R.D., et al., 2003. Remote sensing of surface energy fluxes at $101-\mathrm{m}$ pixel resolutions. Water Resources Research 39 (8), 1221, doi:10.1029/2002WR001775.

Norman, J.M., Anderson, M.C., Kustas, W.P., 2006. Are single-source, remote-sensing surface-flux models too simple? In: D'Urso, G., Osann Jochum, M.A., Moreno, J. (Eds.), Proceedings of the International Conference on Earth Observation for Vegetation Monitoring and'Water Management, vol. 852. American Institute of Physics, pp. 170-177.

Ochs, G.R. Wilson̂, JJ., 1993. A Second-Generation Large-Aperture Scintillometer NOAA Tech. Memo, ERL WPL-232, NOAA Environmental Research Laboratories, Boulder, Co. Publ., 177, 117-32.

Panofsky, H.A., Dutton, J.A., 1984. Atmospheric Turbulence: Models and Methods for Engineering Applications. John Wiley and Sons, New York, 397 pp.

Raupach, M.R., Finnigan, J.J., 1995. Scale issues in boundary layer meteorologysurface-energy balances in heterogeneous terrain. Hydrological Processes 9 (56), 589-612.

Santanello, J.A., Friedl, M.A., 2003. Diurnal covariation in soil heat flux and net radiation. Journal of Applied Meteorology 42 (6), 851-862.

Sellers, P.J., Heiser, M.D., Hall, F.G., Verma, S.B., Desjardins, R.L., Schuepp, P.M., MacPherson, J.I., 1997. The impact of using area-averaged land surface properties - topography, vegetation condition, soil wetness - in calculations of intermediate scale (approximately $10 \mathrm{~km}^{2}$ ) surface atmosphere heat and moisture fluxes. Journal of Hydrology 190 (3-4), 269-301.

Shuttleworth, W.J., Gurney, R.J., 1990. The theoretical relationship between foliage temperature and canopy resistance in sparse crops. Quarterly Journal of the Royal Meteorological Society 116, 497-519.

Shuttleworth, W.J., Yang, Z.-L., Arain, M.A., 1997. Aggregation rules for surface parameters in global models. Hydrology and Earth System Sciences 2, 217226.

Su, Z., 2002. The surface energy balance system (SEBS) for estimation of turbulent heat fluxes. Hydrology and Earth System Sciences 6, 85-99.

Sugita, M., Brutsaert, W., 1991. Daily evaporation over a region from lower boundary layer profiles. Water Resources Research 27, 747-752.

Watts, C.J., Chehbouni, A., Rodriguez, J.-C., Kerr, Ŷ.H., Hartogensis, O.K., De Bruin, H.A.R., 2000. Comparison of sensible heat flux estimates using AVHRR with scintillometer measurements over semi-arid grassland in northwest Mexico. Agricultural and Forest Meteorology 105, 81-89.

Webb, E.K., Pearman, G.I., Leuning, R., 1980. Correction of flux measurements for density effects due to heat and water vapor transfer. Quarterly Journal of the Royal Meteorological Society 106, 85-100.

Wesely, M.L., 1976. The combined effect of temperature and humidity fluctuations on refractive index. Journal of Applied Meteorology 15, 43-49.

Zhang, L., Lemeur, R., 1995. Evaluation of daily evapotranspiration estimates from instantaneous measurements. Agricultural and Forest Meteorology 74, 139-154. 